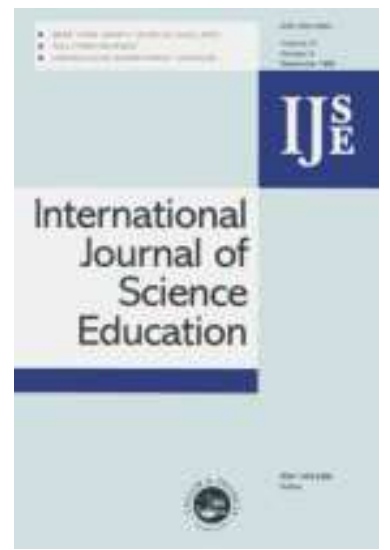

\title{
A three-dimensional approach and open source structure for the design and experimentation of teaching learning sequences: the case of friction
}

\begin{tabular}{|r|l|}
\hline Journal: & International Journal of Science Education \\
\hline Manuscript ID: & TSED-2008-0190.R1 \\
\hline Manuscript Type: & Research Paper \\
\hline Keywords: & physics education \\
\hline Keywords (user): & teaching learning sequence, teacher education, friction \\
\hline
\end{tabular}

\section{$\diamond$ ScholaroNE" \\ Manuscript Central}




\title{
A three-dimensional approach and open source structure for the design and experimentation of teaching learning sequences: the case of friction
}

\begin{abstract}
We have developed a teaching learning sequence on friction based on a preliminary study involving three dimensions: an analysis of didactic research on the topic, an overview of usual approaches, and a critical analysis of the subject, considered also in its historical development. We found that mostly the usual presentations do not take into account the complexity of friction as it emerges from scientific research, may reinforce some inaccurate students' conceptions and favour a limited vision of friction phenomena. The TLS we propose begins by considering a wide range of friction phenomena to favour an initial motivation and a broader view of the topic and then develops a path of interrelated observations, experiments and theoretical aspects. It proposes the use of structural models, involving visual representations and stimulating intuition, aimed at helping students build mental models of friction mechanisms. To facilitate the reproducibility in school contexts, the sequence is designed as an open source structure, with a core of contents, conceptual correlations and methodological choices, and a cloud of elements that can be re-designed by teachers. The sequence has been tested in teacher education and in upper secondary school, and has shown positive results in overcoming student difficulties and stimulating richer reasoning based on the structural models we suggested. The proposed path has modified the teachers' view of the topic, producing a motivation to change their traditional presentations. The open structure of the sequence has facilitated its implementation by teachers in school in coherence with the rationale of the proposal.
\end{abstract}


A teaching learning sequence on friction

\section{Research on teaching learning sequences and our approach}

Starting from results on student conceptions and learning processes related to specific subjects, research in science education has arrived to a "more nuanced" analysis of the problem of designing teaching and learning sequence (TLS) (Méheut \& Psillos 2004). Many different approaches have been proposed (Tiberghien 1996, Lijnse 1995, Lijnse \& Klaassen 2004, Kattmann et al 1997, Komorek \& Duit 2004, Leach and Scott 2002, Viennot et al. 2002, Psillos et al. 2004, Méheut 2004, Andersson et al. 2005). We want to contribute to this debate by presenting an example of construction of a TLS from its design to its analysis in teacher preparation courses and its implementation in high school classes.

The use of research-based TLSs in teacher preparation is an interesting problem to study for the crucial role of teachers in disseminating innovation in the school. A great deal of research (Hirn \& Viennot 2000, Psillos et al 2005, Pinto 2005, Viennot et al. 2005, Sassi et al 2005, Stylianidou et al 2005) has focused both on teacher training projects and experiences, and on the study of the teacher's role as a transformer of the educational intentions of programs and researchers. Andersson et al. (2005) and Eylon \& Bagno (2007) argue that researchers and teachers should work together to design teaching sequences and assess their effectiveness.

Our experience suggests that, to be actually engaged in renewing their teaching and to implement the research based proposals in a correct way, teachers should feel a need of enlarging their own view of the topic and of reorganizing its presentation in a new way. In other words, we think that a personal motivation to restructure their own understanding of the topic can be a strong lever for teachers towards a change of their teaching. We call this cognitive motivation or content related motive, in opposition to motivations related to pedagogical aims or didactic efficacy.

\section{Our approach}

Our approach is based on a critical reflection on content matter taking into account the students' common difficulties and tendencies of reasoning found by didactic research and also the 
A teaching learning sequence on friction

common treatments actually used in schools. The need of a critical analysis of the content matter in a didactical perspective was stressed by several researchers, for example by Chevallard (1991) who introduced the idea of didactical transposition and by Kattmann et al (1997) and Komorek and Duitt (2004) in their model of educational reconstruction.

Thus, the design of a sequence requires a preliminary study involving three dimensions:

S1 - analysis of didactic research on student conceptions and previous TLS's on the topic;

S2 - overview of the usual treatments (textbooks, common teaching practices);

S3 - critical analysis of the scientific subject, including its historical development, together with its practical applications.

To bridge the gap between research project and school reality and, to facilitate the reproducibility in an actual classroom context, the sequences are designed in a form that we call an 'open source structure'. This means that there is a core of contents, conceptual correlations and methodological choices with a cloud of elements that can be re-designed, omitted, or added by the teacher, who may thereby create new versions of the sequence. Some elements redesigned by the teachers can be included in the standard version issued by the research group. In this sense, the teachers' work provides useful feedback that allows us not only to test the effectiveness of the proposal and to identify its points of weakness, but also to enrich it with new elements. A variety of approaches is expected in the actual organization of educational activities, depending on the constraints of the classroom and teacher preferences.

In the following sections results of the preliminary study dealing with friction phenomena are summarized, then objectives and content of the sequence are described; finally, results of its experimentation are reported. 
A teaching learning sequence on friction

\section{Preliminary study}

\subsection{Analysis of didactic research on friction: student conceptions and teaching sequences}

Research regarding students' conceptions has singled out specific difficulties with friction between solids (Caldas \& Saltiel 1995, Besson 1996, Caldas 1999). Students rarely acknowledge that friction forces can play a motive role: friction is almost exclusively considered as resistive. Friction in solids is often represented by one force only, opposed to the 'actual' motion and not to the relative motion between the two solids in contact. In the case of horizontal motion of two objects placed one on top of the other, with an external force applied to one of the two, a friction force is considered to act on the solid placed on top, seldom also on the object placed underneath (over-under effect). In the case of vertical motion (an object leaning against a vertical surface moving with a horizontal acceleration; a cylinder placed inside a ring), a wide majority of students think there exists a single friction force, acting on the object in motion or stimulated to .move. It is also commonly thought that a solid can be dragged by another solid without necessarily requiring the presence of a force to act on it explicitly (dragging effect). In addition, there is a tendency to identify normal force with weight, a trend favoured by the examples proposed in handbooks, which focus too much on situations of horizontal motion in which the normal force is equal to weight.

We found few researches concerning teaching proposals on friction.

With the specific objective of helping students to correctly predict the direction of the static friction force, Caldas \& Saltiel (2000) proposed a teaching sequence based on the use of a didactic model of friction mechanism, the model of the brush. With the same objective, Viennot (2002, chap. 2) experimented a short teaching sequence based on a different model, the model of rigid and interlocked asperities.

Corpuz \& Rebello (2006) conducted individual teaching interviews with university students to investigate the progression of students' mental models on microscopic explanations of friction. 
A teaching learning sequence on friction

The interviews, lasting two hours, involved simple experiments on sliding friction between blocks and sheets of different materials and roughness. The aim was to make students progress from certain common ideas (e.g. friction always increases with surface roughness and it is independent of apparent contact area) towards a more sophisticated scientific conception.

Ringlein and Robbins (2004) propose a teaching approach to friction between solids for university students, based on the use of computer simulations of the interactions on the atomic scale between the surfaces in contact.

All these researches concerned specific and limited aspects of the topic, whereas our objective is to elaborate a more complete and global approach to teach friction phenomena.

\subsection{Teaching friction: how it is usually handled and students' difficulties}

In secondary school and in the first two years at university, friction is generally presented as a marginal topic. It is dealt with briefly in the chapter on mechanics in an abstract and schematic way, based on the 'miraculous' simplicity of the classic laws of static and kinetic friction between solids, of rolling friction and friction in fluids. Thus all the complexity and variety of these phenomena, which have been the object of numerous studies, both ancient and recent, go unrevealed. As Hahner and Spencer (1998) write, 'Though simply expressed, the laws of friction encapsulate a host of microscopic and nanoscopic phenomena whose elucidation has become one of the most fascinating pursuits in applied physics'. Proposing an early schematization may turn out to be detrimental to the understanding of real phenomena and runs the risk of confining the study of physics to an abstract world of idealized objects. This can result in two possible negative effects for students: taking the idealized objects for reality, or considering physics as a body of theories with no relation with the real world and, therefore, of little or no interest. Apart from a brief mention of the effect of the 'roughness' of surfaces, the solid bodies between which friction takes place are nearly always considered as rigid bodies. This schematization, acceptable and useful for many purposes, hinders any attempt to create an image of the mechanisms which 
A teaching learning sequence on friction

can serve as the basis for a causal explanation of friction. This is just the image that many students seem to need in order to be able to understand physical situations, as previous research has proved (Brown 1993, Ogborn 1993, Chabay \& Sherwood 1999, Gutwill et al 1996, Psillos 1995, Besson \& Viennot 2004). In this case, the schematization is sufficient to calculate, on the basis of simplified laws, the physical quantities requested in exercises, but is unable to help the student understand the physical situation (Besson 2004). We think that the use of structural models, involving visual representations and stimulating intuition, can help students overcome some common difficulties and build mental models of mechanisms producing friction. In addition, they can provide a bridge towards richer explanations, and produce new questions and inquiries.

\subsection{Analysis of the physics content, also in its historical development}

Friction is omnipresent in everyday life and in technology, and represents a good example of the interface between abstract and formalized theories, technological objects and the irregular reality of daily experience. At the same time, the topic has its history and recent developments and issues still to be discussed (Krim 2002, Besson 2006, 2007). When we consult some modern treatises of tribology (Quinn 1991, Williams 1994, Persson 1998, Bhushan 2002), we realize how complex the topic is and how vast the problems, the research, the applications and the theories are. Amongst all this material a choice has to be made of content-matter, models and examples suitable for secondary school students. A balance must be found between the need to simplify and shorten, in accordance with the school objectives, the students' level and the time available, and the demand for non-obsolete content matter and, thus, the need to take recent developments into account. The latter problem is common to most scientific subjects but, in the case of friction, it takes on a particular hue because some of the recent developments are unknown to most teachers and many experimental and theoretic results, not even the very recent ones, are in contrast with the laws normally proposed in physics textbooks. 
A teaching learning sequence on friction

For sliding friction between solids, handbooks generally present the three classic laws, attributed to Amontons (1699) and Coulomb (1785), according to which the magnitude $F$ of the friction force is proportional to the magnitude $W$ of the normal force, independent of the area $A$ of the contact surfaces and, in the dynamic case, independent of the speed $u$.

However, for some materials, relations have been found of the type $F \propto W^{n}$, with $n<1$, and therefore a friction coefficient decreasing with the load (e.g. textile fibres, polymers, numerous rocks). The research on nanometric level friction (nanotribology) has found that in many cases friction is not proportional to the load, for example, between a silicon tip and a layer of $\mathrm{C}_{60}$ it is $F \propto W^{2 / 3}$ (Carpick \& Salmeron 1997). In many cases, the relation between friction force and load is complicated and cannot be expressed by a simple mathematical formula. Moreover, there are various well-known sticky materials, which present friction even without a load or with a 'negative' load, such as plasticine, putty, resin... Similar behaviour can also be observed in nanotribology experiments. Many measurements fit with a relation of the form $F=\mu W+k A$, where a purely adhesive term $k A$, proportional to the area, is present, and non-zero friction for a zero load is foreseen. In the past there had already been doubts about the general validity of these laws (S. Vince 1785, Coulomb 1785). Coulomb explains some experimental results as the effect of 'cohesion' between the surfaces, proportional to the area and independent of the load: 'there is another type of resistance, in the friction between surfaces, independent of the load and proportional to the surface areas', which adds to the effect proportional to the load. Moreover, the maximum static friction force depends on the duration of contact, as Coulomb had already observed: it increases with time, reaching a limit value after a time depending on the materials. The dependence of the kinetic friction force on velocity should be viewed even more problematically. According to Bhushan (2002), the third rule of friction, which states that friction is independent of velocity, is not generally valid: there are many materials and situations in which this law is valid, but this does not happen in general. 
A teaching learning sequence on friction

This analysis shows that a criterion to be considered in designing a TLS is that a pertinent and satisfactory knowledge of friction phenomena can be acquired only by taking into account the diversity and complication of the behaviour of materials, and by working with rules and laws valid in many cases but not in general, and with some approximation. Moreover, to show the relevance of friction for many everyday activities it is necessary to present various situations and various kinds of friction phenomena (sliding, rolling, drag, internal friction), emphasizing the differences between such phenomena, but also the properties they share, in causing energy dissipation and permitting the establishing of equilibrium after motion.

Concerning the mechanisms at the origin of friction, various models were proposed in the past and have been the object of doubts and controversies. According to Amontons and Coulomb, the origin of sliding friction lies mainly in the interlocking and deforming of the surface asperities of the materials, Desaguliers (1734) and Vince (1785) emphasize the importance of adhesion, Tomlinson (1929) stresses the role of phononic energy dissipation, Bowden and Tabor (1950) elaborate the model of adhesive junctions. Today different mechanisms are considered, the relevance of which varies according to the situation (adhesion, deformation and ploughing of surfaces, elastic hysteresis, breaking of asperities and wear) and models at a microscopic scale are proposed (Ringlein and Robbins, 2004). It is interesting that many models of friction proposed in the past have been modified and improved but not abandoned, so that history can supply useful resources, in terms of models, mechanisms and experiments, to help student understand friction in a wider and more complete way.

From this analysis it stems that a variety of models should be proposed and discussed with the students to provide tools for interpreting and explaining friction phenomena.

\section{Objectives and didactical choices for a TLS on friction}

The analysis summarized in section 2 led us to define the specific objectives of the sequence:

A) To overcome some common errors and difficulties identified by research (see sec. 2.1), in 
A teaching learning sequence on friction

particular:

A1) the difficulty of considering the static friction force as a force that can produce motion and varies in magnitude and direction depending on the external force;

A2) the tendency to think that there exists only one friction force, forgetting the one acting on the 'passive' object (i.e., not subject to an external 'driving' force) and/or on the object placed below;

A3) the difficulty in understanding the role of static friction in rolling and in recognizing the different direction of the friction force in the cases of driving and non-driving wheels.

B) To correct some trends in the usual presentations of the topic (see sec. 2.2), such as excessive focus on horizontal motion (B1), consideration of friction almost exclusively as a disturbance to be minimized (B2), presentation of the Amontons and Coulomb’s laws as general laws (B3).

C) To help students develop a "modern" vision of friction as a topic connected with many others and still studied in physics research and, at the same time, to guide them to acquire a simplified but operational idea of the mechanisms producing friction and to elaborate explanations and qualitative predictions.

Taking these objectives as a staring point, we made the following choices:

$\checkmark$ Present friction as an almost omnipresent set of phenomena that are crucial for most everyday activities and are very different from each other, although with common traits, and thus propose an overview of this wide phenomenology, including friction between solids, drag in fluids and internal friction. This in order to reduce both the risk of uncritical acceptance of formal descriptions and that of considering friction in a schematic and stereotypical way.

Start the sequence straightaway by giving examples where friction is considered both as a positive 'resource' and an 'obstacle' or 'loss' and by presenting friction as a central object of study and not just as a 'disturbance' to be eliminated. We aim to oppose the 
A teaching learning sequence on friction

idea, supported by the use in school labs of devices minimizing friction, that Mechanics studies only situations without friction.

$\checkmark$ Emphasize how friction is necessary to establish equilibrium after stress or motion. Such an observation aims at drawing attention to a fundamental aspect, the relevance of which is often neglected or ignored. This is also propaedeutic to the study of energy dissipation.

$\checkmark$ Contrast the ideas that friction always has a resistive effect, generates a force always opposed to motion, and acts only on the object in motion or induced to move.

Avoid overemphasis on situations with horizontal friction forces, which can favour identification between normal force and weight. For this purpose, we suggest presenting at the outset examples with vertical friction force where the normal force either has no relation to weight or is not equal to weight. Moreover, even in the case of pressing force equal to weight, it must be emphasized that this force is not the weight. For this reason, in our sequence, the symbol $F_{n}$ is used instead of $W$, which is common in friction literature but may suggest the idea of weight.

Propose appropriate structural models which allow, although to a limited extent, reasoning, interpretations and predictions and thereby more critical knowledge. The incompleteness of the model is discussed immediately, together with the degree to which it fits physical reality, i.e., its similarity to material elements and mechanisms which really exist. These models have an explanatory function and are cognitively fertile because they stimulate research into the entities and processes which are presumed to exist within the material system under study and thereby favour more critical knowledge.

\section{Description of the sequence}

The sequence is organized into six parts. Rolling friction is not dealt with explicitly; it is merely referred to in the first and fourth part of the sequence. Parts $a$ ), b), c) and e) constitute the essential core of the designed sequence. Part $d$ ) can be skipped without negatively impacting the 
A teaching learning sequence on friction

coherence of the sequence, or else it can be placed after the other parts. In any case, it should be treated only when students have already studied torques and rotational motion. Part $f$ ) can be treated after the others, once the fundamental concepts of energy have been introduced.

In what follows, we describe the main activities of the sequence. A more detailed description of some experiments can be found in (Authors 2007).

\section{a) Introductory observations and experiences}

An initial overview introduces the subject by showing the amplitude and variability of its phenomenological aspects. A motivating question is 'What would happen if there were no friction?' How could simple daily activities such as picking up a bottle, walking, weighing with a spring scale, pouring liquid into a container, rounding a curve in a car, carrying glasses and cups on a tray, playing football, take place without friction? The observation of damped oscillations of various liquids and of two different metal wires introduces the ideas of internal friction and elastic hysteresis, which will be addressed again in part $f$ ) of the sequence. Other simple demonstrations illustrate the role of adhesion and the behaviour of sticky materials.

\section{b) Definition of descriptive quantities and first qualitative relationships}

The descriptive quantities necessary to start a scientific treatment are introduced (normal force or load, friction force, contact area) and experiments are proposed, thereby preparing and motivating more quantitative experimental investigations. In order to oppose the students' tendency to identify normal force with weight, experiments are performed in which a vertical friction force is present and the normal force is not related to weight. The students use their finger to push small wooden boards against a wall. We provide wooden boards of equal width and length but varying thickness, and with one side covered with cloth or paper. Students observe that by varying the horizontal force exerted, they can either prevent or allow the board to slide along the wall. The same experiments are then repeated by pushing with a force sensor to measure the force. This experiment constitutes a first exploration, without a systematic collection 
A teaching learning sequence on friction

of data, but the students record the measured values and are encouraged to propose hypotheses regarding the relationships among the physical quantities involved. Thereafter a first conceptual framework is provided in terms of Newton's laws, stressing the interdependence of the three forces involved: pressing normal force, tangential force, friction force. The teacher introduces other ways to produce a normal force: a magnet that presses a piece of iron against a glass and a wooden paddle, accelerated in the horizontal direction that presses against a block (so that for sufficiently large acceleration, the block does not fall).

\section{c) Phenomenological laws of static and dynamic friction}

Three demonstrations are used to support the idea that two friction forces occur on the two surfaces in contact, in accordance with Newton's third law: a block is pulled while placed on a long strip of paper, on a woollen scarf, and on a small cart. Students grasp the idea that the paper, the scarf and the cart are dragged by the block, due to the friction force exerted by it. A more systematic experiment is performed to search for regularities and phenomenological laws and to encourage and motivate the search for explanatory models. The motion of blocks on horizontal planes is studied by using force and motion sensors and a computer data acquisition system. Working in small groups, students construct graphs of the applied force versus time, and evaluate the dependence of friction force on normal force and on contact area.

\section{d) Static friction and rolling}

The knowledge acquired is applied to study the mechanism of rolling, which is a challenge for many students (Rimoldini \& Singh, 2005). By means of simple experiments, explanations and drawings, a logical sequence is proposed that begins with the analysis of the rotation of a cube and of an octagonal prism, and culminates with a rolling cylinder, considered as the limit case of a prism with many faces (Figure 1). The analysis stresses the role and direction of the static friction force in rolling. Two cases are considered: a) a cylinder pulled by a force applied to its axis; b) a cylinder rolling because of the action of a torque. The students are asked to predict the 
A teaching learning sequence on friction

direction the friction force will take. For this purpose we propose an experiment (see also Authors 2005) in which a cylinder is lying on a small trolley and two pencils are placed on the table in a vertical position immediately in front of and behind the trolley (Figure 2). When the cylinder is put in motion, one of the two pencils is pushed by the trolley and falls. By observing which pencil falls, students can deduce the direction of the friction force. Short films on these experiments are available at the URL of the authors.

\title{
Insert here Figures 1 and Figure 2
}

\section{e) Surface topography and mechanisms producing friction}

The classical laws of friction are presented as phenomenological laws which are valid in many cases but not in all, and require an explanation based on the properties of the bodies in contact and on underlying phenomena. Some examples are given that stand in contrast to these laws. For this purpose, students perform experiments in which the surfaces in contact (wooden blocks and table) are covered with transparency films and/or rubber sheets. They find a friction force which is not proportional to the normal force and which depends on the contact area.

The problem of the topography of surfaces and the distinction between apparent and real area of contact are treated. Pictures are used to illustrate the irregular aspect of the surface of apparently smooth objects when viewed on a micrometric scale (Figure 3), and the behaviour of asperities under load (increase of both the area of each contact and of the number of contacts).

\section{Insert here Figure 3}

\begin{abstract}
Next, we address the mechanisms producing friction stressing that a variety of phenomena exists, the relevance of which varies according to the situations and materials considered. The main mechanisms are presented in a descriptive and intuitive way: adhesion between the asperities of surfaces, deformation and tracking or scratching of surfaces, impact and interlocking among
\end{abstract}


A teaching learning sequence on friction

asperities, wear due to the relative motion between the bodies in contact, and the effect due to particles trapped between the surfaces (third body). Some historical explanatory models of sliding friction phenomena are considered together with more recent ones. We prepared a written overview (available at the URL of the authors) for teachers and another one for students to illustrate, in a simplified way, the experimental data, theoretical explanations, and historical development of the scientific research on the topic.

\section{f) Friction phenomena from the point of view of energy}

The teacher presents simple qualitative experiments suggesting the transfer of energy to internal parts of a system: damped oscillations of metal blades and of cylindrical boxes containing lead pellets, crashing a trolley with a variety of metal blades against a wall (Figure 4).

\section{Insert here Figure 4}

The damped oscillations of the metal blades are an analogy providing an explanatory model for energy exchanges due to friction. The surfaces are represented with a large number of asperities, which can be deformed and crushed under the load, and interact through adhesion and/or interlocking. The relative motion of the two objects causes a deformation of asperities, thus transforming macroscopic energy into elastic energy within asperities (Figure 3). Subsequently, the asperities split up and oscillate with a rapid damping, thus transforming mesoscopic elastic energy into microscopic thermal energy. A quantitative analysis of the energy balance may be offered, if the level of the students permits (Besson 2001).

\section{Experimentation of the sequence: methods and samples}

Our TLS experimentation plan aims both at involving both secondary school pupils and student teachers and at favoring stronger interaction between high school and university.

It includes four phases. A preliminary phase consists in presenting experiments or lectures to small groups or individuals. This is intended to identify student reactions to certain aspects, and 
A teaching learning sequence on friction

to prepare a sequence based on student responses (evidence-based TLS). Thereafter the sequence is tested with student teachers (in the present case, three groups of student teachers: $n=24,22$ and 12 in 2006, 2007 and 2008, respectively, for a total of $n=58$ ). The student teachers follow the same type of path we designed for secondary school students, but are guided to reflect on the content and cognitive concatenation of the proposed path, on common student difficulties and on other facets of their future teaching in the classroom. Subsequently, student teachers present the sequence in the secondary school classes in which they are performing their teaching training, by adapting it to the specific school situation (in the present case, eight student teachers used it in four classes). Moreover the sequence is proposed to expert teachers, who adapt and use it in their classes (three classes, in the present case).

As noted at the end of section 1, we organized the sequence in an open structure to allow teachers to introduce changes in accordance with their specific teaching situation, while maintaining the core of the rationale, objectives and methods of our design. The teachers testing the sequence receive a 'suitcase' containing the material for some experiments, as well as three documents: i) a detailed description of the sequence; ii) a presentation of the main ideas and didactical choices, and common cognitive problems and difficulties of students; iii) a deepening of the content based on a historical review of the research on friction.

In the following, we present the results of the experimentation with student teachers and we briefly report on the implementation of the sequence with secondary school students.

\section{Testing the sequence with student teachers}

The experimentation with student teachers included six work sessions of two hours each. A pretest was given before the sequence; the student teachers compiled worksheets during the laboratory activity, wrote reports on their activities and prepared a teaching plan on the topic. A post-test was given two weeks after the end of the sequence.

Evaluation was carried out in the form of an internal evaluation, i.e., without a comparison with 
A teaching learning sequence on friction

control groups, but observing indicators of cognitive changes in the student teachers. The peculiarity of the population allowed, in some way, to use the same experimental group as a selfcontrol group of the cognitive acquisitions obtained in standard university education. Indeed, the group was made up of future physics teachers who had completed the programs required for a degree in physics or mathematics or engineering. The study of mechanics and of friction was included in their introductory physics courses. The comparison between the initial and final tests can be interpreted as a comparison between the long-term results of a typical Italian university program and the short-term results of our sequence.

The material we analyzed includes the following documents: answers to pre-test and to post-test; worksheets filled in by each student teacher during the working sessions; reports on the experiments carried out in groups; doubts and comments expressed by the student teachers; proposals for secondary school teaching plans elaborated by student teachers; reports of student teachers who tested the sequence on friction in their teaching practice.

The questions of the post-test are designed to be strictly related to the objectives indicated in section 3, as Table 1 shows. To check whether some common difficulties identified by research have been overcome, we introduced both in the pre- and post-test some questions similar to the ones reported in the literature (Caldas \& Saltiel 1995, Caldas 1999, Besson 1996).

Table 1. Correspondence between the questions of the post-test and the objectives of the sequence

\begin{tabular}{|c|c|c|c|c|c|c|c|c|c|}
\hline Question & 1 & 2 & 3 & 4 & 5 & 6 & 7 & 8 & 9 \\
\hline Objectives & A2 & A1 & B3 & B3,C & A2,B1,B2,C & A1,B2,C & A1,A3,B2 & A1,A2,C & A1,B2 \\
\hline
\end{tabular}

The questions of the pre-tests and post-tests to which we will refer in the next sections are listed in the Appendix. The 2006 post-test involved nine questions, those of 2007 and 2008 included only four of the nine questions used in 2006 (namely, questions 3, 6, 8, 9 ). 
A teaching learning sequence on friction

In what follows, we present some results drawn from the available evaluation data, with reference to the objectives indicated in section 3 .

\subsection{Objectives A1, A2, A3. Role and direction of friction forces}

\section{Friction force as motive force}

The pre-test results show that only $16 \%$ of the student teachers grasped the motive role of the friction force on the 'passive' object (block B of question 3, placed on a cart pulled by a force $\boldsymbol{F}$ ) and only $21 \%$ correctly drew the direction of the friction force on the block ( $61 \%$ indicated a friction force opposite to $\boldsymbol{F}$ and $18 \%$ did not indicate any friction force on the block). These results fit well with the ones found by Caldas and Saltiel $(1995,1999)$ with university students.

A similar situation is presented in question 6 of the post-test, where a tray on a cart is considered. The cart is pushed in three different ways: first it is accelerated, then it is kept in uniform motion, finally it is slowed and stopped. Almost all (93\%) wrote that the friction force is the motive force acting on the tray. A clear majority indicated the correct direction of the friction force acting on the tray (89\% for the acceleration phase, $82 \%$ for the acceleration and deceleration phases and $76 \%$ for all phases). An analysis performed with the $\chi^{2}$ test shows that the difference between the two tests is statistically significant ${ }^{1}$ at a confidence level lower than $0.01 \%$. A correct answer for both phases of acceleration and deceleration seems to reveal a secure understanding of static friction force as the force causing motion. The marked difference between pre-test and post-test may be interpreted as a positive effect of the sequence.

A similar situation is proposed in question 8 of the post-test: a block, pulled by a horizontal force, drags a pad below it. Here the results are even more clearly positive: all students correctly indicated the friction force exerted on the pad by the block as a dragging force of the pad.

\footnotetext{
L

${ }^{1}$ The use of the $\chi^{2}$ test in this case is questionable, because we did not compare two independent groups, but the same group in two different situations. Nevertheless, the net result we obtained is useful to confirm, with a reliable quantitative method, the qualitative impression that data in the table provide "prima facie".
} 
A teaching learning sequence on friction

\section{Friction force on a passive object placed below another body}

As mentioned in section 2.1, physics education research has shown that there is a strong tendency to think that there is only a single friction force, and to forget the force applied to a body below another body. A situation involving this issue is presented in questions 1 and 8 of the post-test. The results are clear: all students correctly indicated the friction force on the object placed below (a pad and a table). By contrast, in the case of a similar pre-test question (question 2), only half of the students answered correctly. It is interesting that, in their reports on the second session, two student teachers wrote explicitly that they were 'in doubt if there is a force of friction on the floor due to the block'.

\section{Static friction on driving and on passive wheels}

In this connection, we have no data on student teacher reasoning before the use of the sequence. Thus a comparison of results can be done only with regard to a generic population of university students (Caldas 1999, Caldas \& Saltiel 1995). However, the observations made during the use of our sequence clearly indicate that student teachers had an incomplete or incorrect view of this topic, and they appeared rather surprised by the demonstrations proposed and the conclusions drawn. Question 7 of the post-test presents the situation of an accelerated car with front-wheel drive, and almost all students (91\%) correctly indicated the direction of the static friction forces on the front and rear wheels. As comparison, Caldas (1999) reports only $11 \%$ of correct answers on a similar question among a sample of 75 university students and 49 physics teachers (81\% indicated two forces in the same direction for the front and rear wheels, $26 \%$ in the same direction of the movement and 55\% opposite to it).

\section{Application of learning to a new situation}

We used question 9 of the post-test to evaluate whether students were able to use the knowledge acquired in a new situation. Here we asked for the direction of the friction force applied to an object placed on a carousel rotating at constant speed. $75 \%$ of the student teachers indicated the 
A teaching learning sequence on friction

correct direction, and 70\% provided a sufficiently clear justification. This percentage of correct answers was significantly higher than for the similar question 3 of the pre-test (18\%). This reveals a net improvement in the understanding of physical situations involving friction. Further, since it involves the application of knowledge to a new context, it is an indication of stable and productive cognitive acquisitions.

\subsection{Objective B. Correcting some common trends}

\section{Vertical friction force}

As above remarked in section 2.2, the usual presentations of friction focus mainly on situations in which the friction force is horizontal, which may lead to misunderstandings in cases where the friction force is vertical or oblique. For this reason our sequence presents situations with vertical friction forces from the outset. We included question 4 in the pre-test and question 5 in the posttest to measure the effectiveness of this strategy. We found that most students correctly indicated the vertical friction force for both questions, but with a significant difference: $68 \%$ in the pre-test and $100 \%$ in the post-test. Moreover, in the pre-test only a third of students (36\%) correctly expressed the condition of equilibrium of the object by comparing the friction force with the weight, whereas in the post-test $83 \%$ clearly indicated the friction force as the force that supports the disc, being a force opposite to its weight.

\section{The Approximate and phenomenological nature of Coulomb's laws}

Coulomb’s laws are often presented as general laws, without discussing their status and range of validity. By contrast, our sequence aims to help student understand that these laws are only approximate phenomenological laws that work well in many situations but not in all cases. The effectiveness of our approach can be evaluated only in a qualitative way by student teacher reports and their answers to questions 3 and 4 of the post-test. In these questions they were asked to indicate the results obtained in the experiments and to provide an explanation of the 
A teaching learning sequence on friction

independence of the friction force from contact area. In their answers to questions 3 and 4, 20\% of the student teachers stressed that the independence of the force from the contact area and from the speed is only approximate and/or does not always obtain. Some quotations: 'the force of dynamic friction does not depend on the speed, but sometimes it does'; 'the proportionality between friction force and normal force is only approximate'; 'the usual empirical law does not always apply'. In the report on an experiment, some student teachers (10\%) affirmed that proportionality between the friction force and the normal force was not well respected, and many students (35\%) found a dependence of the friction force on the contact area.

\subsection{Objective C. Use and effectiveness of a mesoscopic model}

Our data indicate that the idea of a mesoscopic model is virtually absent at the beginning of the sequence, and that consciousness of its relevance progressively increases during the use of the sequence. Elements of a model of mesoscopic asperities are frequently mentioned in the answers to questions of the post-test. In question 5, two-thirds of the student teachers produced drawings representing surfaces with mesoscopic roughness. In answer to question 6 involving the explanation of the behaviour of forces, $67 \%$ of student teachers made a drawing representing the mesoscopic surface roughness to explain the friction force in the different situations proposed.

A clue to the effectiveness of the model may come from a cross-analysis of the responses to items $b$ and $c$ of question 6 of the post-test. Of the student teachers who indicated the wrong direction for $\boldsymbol{F}_{\boldsymbol{A}}$ during the phase of increase and/or decrease of velocity, none made drawings related to the model. By contrast, all those who made representations of the model answered correctly. It is worth to note that in this case the drawings of surface roughness were not merely a passive figurative representation, because the asperities were represented as deformed in different ways according to the different accelerations of the system. Thus here the model assumes an operational explanatory role, even if only in a very simplified and schematic way.

Question 4 of the post-test asks for an explanation of the (approximate) independence of friction 
A teaching learning sequence on friction

force from the area. In their answers, a clear majority of student teachers (86\%) make reference to mesoscopic asperities, and also distinguish between apparent and real contact area, thereby evoking a specific characteristic of the model. In addition, almost half (45\%) develop arguments involving the number of asperities and their being crushed on contact. There are also some considerations of local pressure, often including a qualitative explanation of the proportionality between friction force and normal force. There are arguments of the following form: if the area is greater, there are more points of contact, but the local pressure is lower, so there is less crushing of asperities. Some students stressed that the independence of friction force from area no longer applies if the real contact area becomes of the same order of magnitude as the apparent one.

The adhesive junction model was presented in the sequence as one of the main mechanisms generating friction. Here we see the specific characteristics of the model being used by student teachers to support qualitative and quite articulated explanations of non-obvious properties of friction. The reasoning about the links among friction force, normal force and real and nominal contact areas, albeit fairly rough and only sketched, raises the discourse to a more refined level than the simple repetition of fixed rules on idealized objects.

\section{Experimentation of the sequence with secondary school students}

\subsection{Implementation by student teachers during their teaching practice}

Eight student teachers implemented the sequence during their teaching training in four secondary school classes, three of them of grade 11, age 16-17, for a total of 62 students; and one class of grade 9, age 14-15. Two student teachers were engaged for each class in each teaching experiment. The duration of the activities varied from 7 to 10 hours. The content of the sequence and the time devoted to it were adapted to time constraints and to level of the students. Changes were introduced to overcome didactical problems, such as ensuring the coherence of the sequence with the previously covered program; and to solve practical constraints connected to the availability of materials necessary for the experiments. In detail, the main adaptations were: 
A teaching learning sequence on friction

- Parts $a$ (Introductory observations and experiments), $b$ and $c$ (Vertical friction force and phenomenological laws) were presented in all classes; part $f$ was omitted from all classes.

- Part $d$ (Static friction and rolling) was introduced in only two classes. In one it was introduced at the end of the sequence as an opportunity to apply knowledge acquired. The students responded positively to this approach and were very interested in proposing explanations of new phenomena by using what they had previously learned.

- Part $e$ was presented in all classes, although with variations in emphasis and modality.

Most of the critical aspects essential for the coherence and objectives of the sequence were understood and implemented by the student teachers. They agreed with the essential choices at the base of the sequence (see sec. 3): initial exploration of many different phenomena; emphasis on friction as a useful resource and origin of motive forces and not only as an obstacle to motion; attention to cases in which the normal force is not the weight; the use of mesoscopic models to explain possible mechanisms originating friction. The student teachers maintained the same didactical structure as our original sequence with the phases of motivation, qualitative exploration, first formalization, experimental study, systematization and proposal of explanatory models. In the class work they focused on typical student difficulties by posing questions and proposing exercises and experiments (see objectives A1-2-3, section 3). They used experimental devices, images and references from the material we had prepared for the sequence, but they also integrated these materials with tools they found in the school.

An initial test (similar to the one proposed in our sequence) and a final test, including quantitative exercises in addition to our original questions, were administered in each class.

Comments on the experience reported by student teachers, students, and supervising class teachers were very positive. One of the class teachers was deeply interested in the experiments and involved the school technician in the activities and in reproducing the materials of the kit. Other teachers in the school showed interest in the sequence and expressed the intention of 
A teaching learning sequence on friction

introducing this kind of activity in their classes. In this way a slow, informal diffusion of research products takes place.

The experiments and models proposed in our sequence were used in many cases in creative and 'interactive' ways to respond to the needs expressed by students. In this way, a wealth of learning resources became available to the teacher, to be used as needed. For example, a student asked in an introductory lesson, 'Why, instead of "pressing force", do we not simply call it “weight”?' The student teacher responded by presenting the experiments with blocks pushed against the wall to help students discriminate between normal force and weight, and to acquire a broader view of the topic.

\subsection{Implementation by an expert teacher}

An expert teacher used the sequence in three different classes (Exp1, Exp2, Exp3), trying in each class to fit the presentation to the context. Exp1 refers to the experimentation carried out with 16 year old students in their first year of physics study. The teacher used the complete sequence, spacing out the work over a long period and proposing part $d$ ) after a discussion of the elements of the mechanics of systems. In Exp2 the sequence was used with 17 year old students who had already completed the study of mechanics. In this case the teacher used only parts $d$ ), e) and $f$ ) as a complement to an earlier presentation of friction done in the traditional way. Exp3 refers to a trial with 16 years old students who had already studied physics for two years. The sequence was presented over a shorter period of time than in Esp1, and part d) was not included.

In each trial the teacher collected data from a pre-test and a post-test, reports produced by the students after each work session, discussion of exercises and problems, student homework, and a final questionnaire on the whole experience. She prepared short reports on the activities carried out and the results of pre- and post-tests.

The analysis of these data demonstrates the teacher's awareness of the innovations the sequence introduces both in content and in the phenomenology considered, compared to her usual 
A teaching learning sequence on friction

approach. She said that, over time, she felt progressively more comfortable with the experiments and with the rationale of the sequence. Thus, in the last trial, she also prepared simplified versions of some experiments by herself.

Student reports and teacher comments allow us to conclude that main objectives of the sequence were attained by most students. Nevertheless, the results of the post-test, where the teacher introduced traditional quantitative problems together with qualitative and conceptual questions, show that some students still had difficulties in solving traditional exercises. This suggests that some quantitative aspects have to be more explicitly tackled in the sequence, in a manner coherent with the proposed approach, to facilitate the connection between the sequence and traditional textbook exercises, often used by teachers in student assessments.

\section{Conclusions and implications}

Our research has touched upon many aspects involved in the design and experimentation of a teaching sequence.

The design was based on a preliminary study involving three dimensions: analysis of didactic research on the topic, an overview of the usual approaches, and a critical analysis of the scientific subject and its historical development. This study has confirmed the importance of critical reflection on content matter with a view to its reconstruction for teaching purposes.

Our organization of the TLS experimentation aimed at bringing together sequence testing and teacher training. It included a preliminary exploratory phase with small groups, testing of the sequence with student teachers, utilisation of the sequence by the student teachers during their teaching practice in school, and the use of the sequence by expert teachers in their classes.

We aimed also at bridging the gap between research project and school reality, and at facilitating the reproducibility of the sequence in a real classroom context. To achieve these aims, we proposed the sequence in an 'open source structure', with a core of content, conceptual paths and methodological choices, which we consider essential, and a cloud of elements that can be re- 
A teaching learning sequence on friction

designed or omitted by the teacher.

Our sequence testing has provided encouraging results, both from the point of view of overcoming certain typical student difficulties, and of stimulating new and richer reasoning. We have found that the use of structural explicative models had a positive effect for understanding physical situations: the models provided the basis for articulate, qualitative explanations with reasoning patterns, which, although incomplete, reached a much more refined level than the simple repetition of abstract rules based on idealized objects. The broad introduction to the subject by means of a variety of experiments has produced in the students a more complex and articulate view of friction phenomena, and has considerably changed the teachers' approach. Many observations and quotations indicate that teachers felt personal motivation and interest to better and differently understand the topic and that this motivation led to personal engagement to change traditional presentations by introducing the new acquisitions into their teaching. The open source structure of the sequence facilitated its implementation by teachers, in coherence with the rationale of our proposal, thus starting an informal diffusion in real school environments. Implementation in different contexts showed that it was possible to adapt the sequence to the classroom situation without losing the main characteristics of the approach. Teachers demonstrated to be able to make the modifications judged necessary, while maintaining coherence with the rationale of our approach as described in the documents provided to them. Teacher responses provided useful suggestions for the pursuit of this kind of research. In addition, the interest and motivation expressed in these responses was very encouraging for the approach we propose.

\section{References}

Amontons, G. (1699). De la résistance causée dans les machines, Mémoires de l'Académie Royale A, 19/12/1699, in Histoire de l'Académie Royale des Sciences (1732) pp. 206-227. Andersson, B., Bach F., Hagman, M., Olander, C. \& Wallin, A. (2005). Discussing a research 
A teaching learning sequence on friction

programme for the improvement of science teaching. In K. Boersma et al (Eds.) Research and the Quality of Science Education (pp. 221-230). Dordrecht NL, Springer.

Besson, U. (1996). Le frottement solide sec de glissement. Rapport de tutorat, DEA de Didactique de Sciences Physiques, Université de Paris 7.

Besson, U. (2001). Work and Energy in the Presence of Friction: The Need for a Mesoscopic Analysis, European Journal of Physics, 22, 613-622.

Besson, U. (2004). Some features of causal reasoning: common sense and physics teaching. Research in Science \& Technological Education, 22 (1), 113-125.

Besson, U. (2006-2007). Da Leonardo da Vinci alla nanotribologia: storia delle ricerche e delle teorie sui fenomeni d'attrito. Prima parte: Le leggi dell'attrito radente, le teorie della lubrificazione e gli studi sull'attrito volvente. La Fisica nella Scuola, XXXIX (4), 151-162. Seconda parte: Le teorie dell'usura, la sintesi di Bowden e Tabor, l'attrito a livello atomico. La Fisica nella Scuola, XL (1), 16-32.

Besson, U. \& Viennot, L. (2004). Using models at the mesoscopic scale in teaching physics: two experimental interventions in solid friction and fluid statics. International Journal of Science Education, 26 (9), 1083-1110.

Bhushan, B. (2002). Introduction to tribology, John Wiley \& sons.

Bowden, F.P. \& Tabor, D. (1950 and 1964). Friction and Lubrication of Solids, vol. I and II. Oxford, Oxford University Press.

Brown, D. E. (1993). Refocusing Core Intuitions: A Concretizing Role for Analogy in Conceptual Change, Journal of Research in Science Teaching, 30, 1273-1290.

Caldas, H. (1999). Atrito. O que diz a Fisíca, o que os alunos pensam e o que os livros explicam. Vitória-ES, Brazil, Editora da Universidade Federal do Espírito Santo.

Caldas, H. \& Saltiel, E. (1995). Le frottement cinétique: analyse des raisonnements des étudiants. Didaskalia, 6, 55-71. 
A teaching learning sequence on friction

Caldas H. \& Saltiel E. (2000) Les étudiants et les forces de frottement solide: le modèle de la brosse. Le BUP, 822, 471-485.

Carpick, R.W. \& Salmeron, M. (1997). Scratching the Surface: Fundamental Investigations of Tribology with Atomic Force Microscopy. Chemical Review, 97, 1163-1194.

Chabay, R.W. \& Sherwood, B.A. (1999). Bringing atoms into first-year physics. American Journal of Physics, 67(12), 1045-1050.

Chevallard, Y. (1991). La transposition didactique. Grenoble, La pensée Sauvage.

Corpuz , E.G. \& Rebello, N.S. (2006). Students’ conceptual development in the context of microscopic friction: A case study with two students. Proceedings of the NARST 2006 Annual Meeting, San Francisco. http://web.phys.ksu.edu/papers/2006/Corpuz_NARST2006.pdf.

Coulomb, C.A. Théorie des machines simples. Paris, 1785.

Desaguliers, J.T. (1734). A Course of Experimental Philosophy, vol.1, London.

Eylon B-S. and Bagno E. (2006). Research-design model for professional development of teachers: Designing lessons with physics education research. Physical Review Special TopicsPhysics Education Research, 2, 020106, 1-14.

Gutwill, J., Frederiksen, J. \& Ranney, M. (1996). Seeking the casual connection in electricity: shifting among mechanistic perspectives. International Journal of Science Education, 18(2), $143-162$.

Hähner, G. \& Spencer N (1998). Rubbing and scrubbing. Physics Today, Sept. 1998, 22-26.

Hirn, C. \&Viennot, L. (2000). Transformation of Didactic Intention by Teachers: the case of Geometrical Optics in Grade 8 in France. International Journal of Science Education, 22 (4), 357-384.

Kattmann, U., Duit, R., Gropengießer, H. \& Komorek, M. (1997.) Das Modell der Didaktischen Rekonstruktion. Zeitschrift für Didaktik der Naturwissenschaften, 3 (3), 3-18.

Komorek, M. \& Duit, R. (2004). The teaching experiment as a powerful method to develop and 
A teaching learning sequence on friction

evaluate teaching and learning sequences in the domain of non-linear systems. International Journal of Science Education, 26 (5), 619-633.

Krim, J. (2002). Resources Letter: Friction at macroscopic and microscopic length scale. American Journal of Physics, 70, 890-897.

Leach, J. \& Scott, P. (2002). Designing and evaluating science teaching sequences: an approach drawing upon the concept of learning demand and a social constructivist perspective on learning. Studies in Science Education, 38, 115-142.

Lijnse, P. (1995). 'Developmental Research’ as a way to an empirically based 'Didactical Structure' of science. Science Education, 79 (2), 189-199.

Lijnse, P. \& Klaassen, K. (2004) Didactical structures as an outcome of research on teachinglearning sequences? International Journal of science Education, 26 (5), 537-554.

Méheut M. (2004) Designing and validating two teaching-learning sequences about particle models. International Journal of science Education, 26 (5), 605-618.

Méheut, M. \& Psillos, D. (2004). Teaching-learning sequences: aims and tools for science education research. International Journal of science Education, 26 (5), 515-535.

Ogborn, J. (1993.) Approche théorique et empirique de la causalité. Didaskalia, 1, 29-47.

Persson, Bo N.J. (1998). Sliding Friction. Physical principles and applications. Berlin, SpringerVerlag.

Pinto, R. (2005). Introducing Curriculum Innovations in Science: Identifying Teachers’ Transformations and the Design of Related Teacher Education. Science Education, 89, 1-12.

Psillos, D. (1995). Adapting instruction to students' reasoning. In D. Psillos (Ed.) European research in science education, Proceedings of the 2nd Ph.D. Summerschool (pp. 57-71). Thessaloniki.

Psillos, D., Tselfes, V. \& Kariotoglou, P. (2004). An epistemological analysis of the evolution of didactical activities in teaching-learning sequences: the case of fluids. International Journal 
A teaching learning sequence on friction

of science Education, 26 (5), 555-578.

Psillos, D., Spyrtou, A. \& Kariotoglou, P. (2005). Science teacher education: issues and proposals. In K. Boersma et al (Eds.) Research and the Quality of Science Education (pp. 119128). Dordrecht, Springer.

Quinn, T.F.J. (1991). Physical analysis for tribology. Cambridge University Press.

Rimoldini, L.G. \& Singh, C. (2005). Student understanding of rotational and rolling motion concepts. Physical Review Special Topics-Physics Education Research, 1, 010102, 1-9.

Ringlein J. and Robbins M.O. (2004). “Understanding and illustrating the atomic origins of friction,” American Journal of Physics, 72(7), 884-891.

Sassi, E., Monroy G. and Testa I. (2005). Teacher Training About Real-Time Approaches: Research-Based Guidelines and Training Materials. Science Education, 89, 28-37.

Stylianidou F., Boohan R. and Ogborn J. (2005). Science Teachers' Transformations of the Use of Computer Modeling in the Classroom: Using Research to Inform Training. Science Education, 89, 56-70.

Tiberghien, A. (1996). Construction of Prototypical Situations in Teaching the Concept of Energy. In G. Welford, J. Osborne, \& P. Scott (Eds.) Research in science education in Europe: Current issues and themes (pp. 100-114), London, Falmer.

Tomlinson, G.A. (1929). A Molecular Theory of Friction. Philosophical Magazine, 7, 905-939. Viennot, L. (2002). Enseigner la Physique : ruisseaux et grains de sable. Bruxelles, De Boeck Université (English translation: Teaching physics, Dordrecht, Kluwer, 2003).

Viennot, L., Chauvet, F., Colin, P. \& Rebmann, G. (2005). Designing strategies and tools for teacher training: The role of critical details, examples in optics. Science Education, 89, 13-27.

Vince, S. (1785). The Motion of Bodies affected by Friction. Philosophical Transactions of the Royal Society of London, 165-189.

Williams, J.A. (1994.) Engineering Tribology. Oxford, Oxford University Press. 
A teaching learning sequence on friction

\section{Appendix: Questions of the pre-test and of the post-tests}

The questions given to students included other figures that we do not report here for the sake of brevity.

\section{Pre-test}

1) List situations in which friction forces play an important role.

2) A block moves on a table under the action of a horizontal and constant force $\mathbf{F}$. Draw the forces acting on the block and those acting on the table.

3) A block B is set on a cart A, placed on a table. The cart is pulled with a horizontal and constant force $\mathbf{F}$.

\section{Insert here figure 5}

What can happen to block B? Illustrate your answers by drawing the forces acting on B.

4) A wooden block is pressed against a wall by a horizontal force. What can happen to the block? Illustrate your answers by drawing the forces acting on the wall and on the block.

\section{Insert here figure 6}

\section{Post-test}

1) A block moves on a table pulled by a horizontal force $\mathbf{F}$. There is friction between the table and block. List and draw the forces acting on the block and the forces acting on the table.

2) This question refers to the laboratory activity carried out by using a wooden block, initially at rest on the table and then pulled with a force $\mathbf{F}$, measured by a force sensor. The figure represents a graph of force acting on the block as a function of time. 
A teaching learning sequence on friction

a) What is the maximum value of the static friction force?

b) What is the value of the dynamic friction force acting on the block?

c) In what instant of time the block starts its motion?

d) What is the value of the static friction force at the instant $t=1 \mathrm{~s}$ ?

3) List briefly but in detail the main conclusions that you obtained from the laboratory activity carried out on friction between solids.

4) It is generally found that the friction force does not depend, or depends weakly, on the area of the surface of contact. How can you explain this fact?

5) A wooden paddle is held vertical. If a wooden disk is put in contact with the tablet and then released, the disk slides and falls. If the wooden paddle is accelerated horizontally, the disk can remain stationary in contact with the wooden paddle, sharing its accelerated motion.

\section{Insert here figure 7}

a) Explain this phenomenon. What prevents the disc from falling? What supports it?

b) List and draw the forces acting on the disk.

c) Explain the phenomenon by using a mesoscopic model and drawing a sketch of the asperities in the contact between disk and tablet.

6) A tray is placed on a cart, which is at rest. The cart is put in motion with a small acceleration, then moved at uniform motion and finally slowed down until it stops.

\section{Insert here figure 8}

a) What is the force that has set the tray in motion (the tray, not the cart!), making it accelerate? What is the force that caused its velocity to decrease until it stopped?

b) Use an arrow to indicate the static friction force exerted on the tray by the cart: during the phases of acceleration of the cart; during its uniform motion; during its deceleration.

c) Give an explanation of the forces acting on the tray. Use a mechanism based on what 
A teaching learning sequence on friction

may happen on a smaller scale (think of the adhesive junction model). For this purpose, draw a sketch for each phase of motion.

7) A vehicle with front wheel drive accelerates. Indicate the directions of the static friction forces acting on the front driving wheels and on the rear passive wheels. Explain your answers.

8) A wooden block is set on a cloth pad, placed on a table. There is strong friction between block and pad while friction between cloth and table is very small. A constant and horizontal force F is applied to the block.

\section{Insert here figure 9}

a) What types of motion can be observed?

b) List and draw the forces acting on the block.

c) List and draw the forces acting on the pad.

d) Use a sketch to represent the asperities in a small area of the two surfaces in contact (block and pad) while force $\mathbf{F}$ is acting.

9) An object is placed on a carousel rotating at constant speed. Due to friction, the object remains at rest with respect to the carousel, following its rotational motion. Indicate the direction of the static friction force exerted on the object by the carousel. Explain your answer. 


\section{Figures}

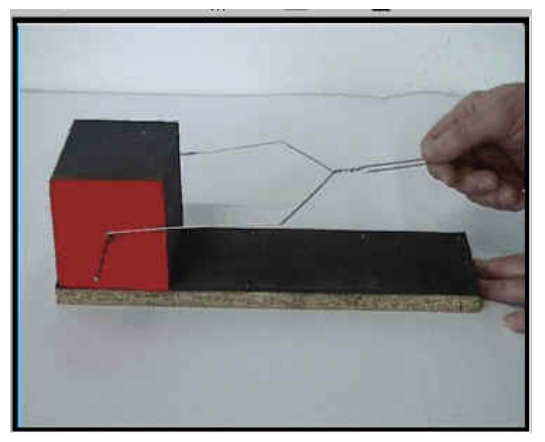

Fig. 1. Rotation of a cube

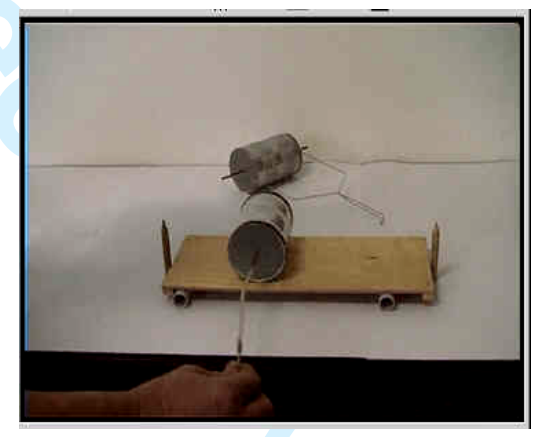

Fig. 2. Experiment with a cylinder and two pencils
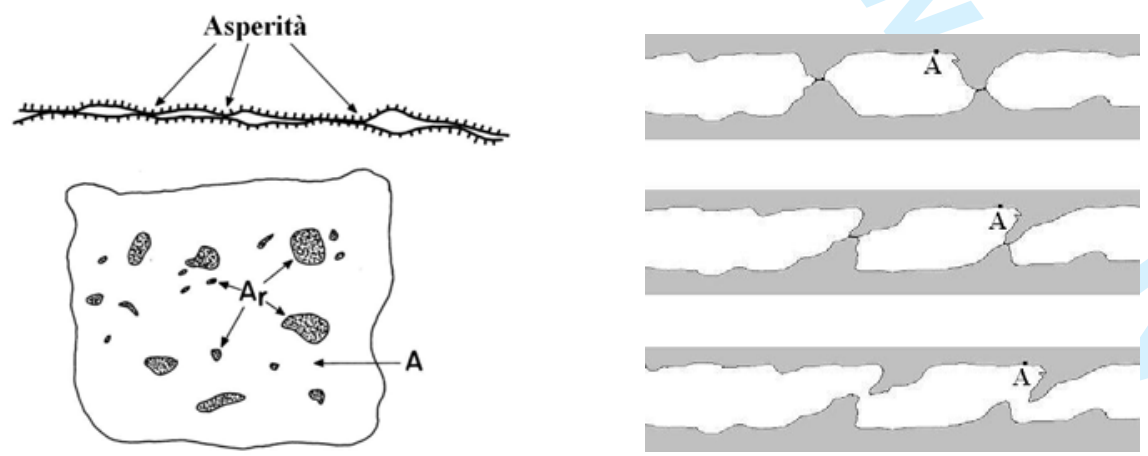

Fig. 3. Topography of surfaces and deformation of asperities in the adhesive junctions model 


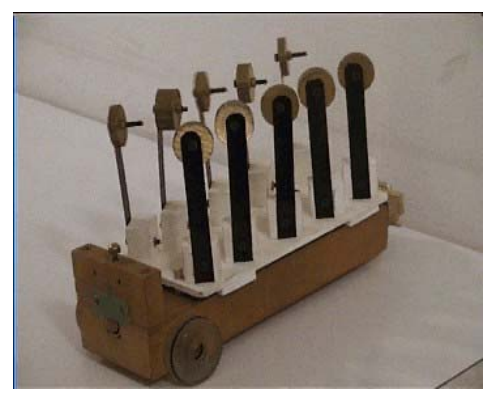

Fig. 4. Cart equipped with a variety of metal blades. When the cart collides against a wall, most of the translational kinetic energy of the cart is transferred to the blades, which start oscillating, so that the collision becomes strongly inelastic and the rebound speed is almost zero.

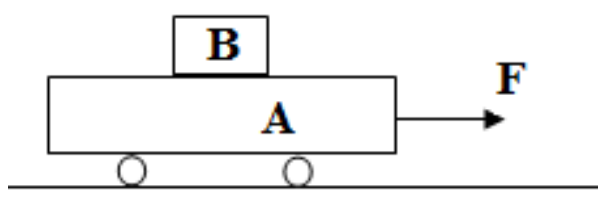

Fig. 5. A block on a cart pulled by a force 
Figure 7. A wooden paddle that is accelerated horizontally pushes a disk, thus provoking a vertical friction force, which can counteract the weight of the disk.

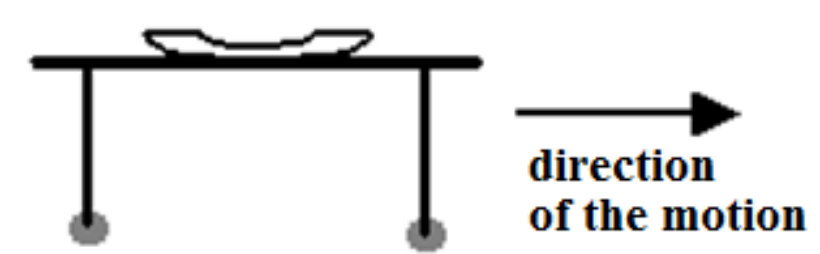

Fig. 8. A tray on a cart.

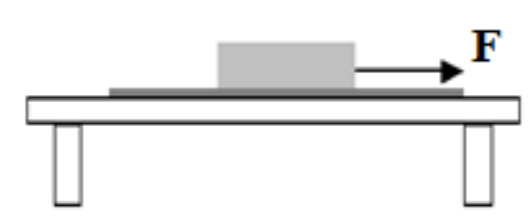

Figure 9. A block set on a cloth pad is pulled by a horizontal force. 